\title{
Motivasi Host Couchsurfing.Com Area Denpasar Menjadi Pemandu Wisata Traveler
}

Eti Yulistianaa, 1, I Gusti Agung Oka Mahaganggaa, 2

1eti.yulistiana@yahoo.com,2okamahagangga@unud.ac.id

a Program Studi S1 Destinasi Pariwisata, Fakultas Pariwisata,Universitas Udayana, Jl. Dr. R. Goris, Denpasar, Bali 80232 Indonesia

\section{Abstract}

Couchsurfing.com is social media which make traveler and local meet in tourist destination. Which is they dont know each other before meet. Share about anything and explore the tourist destination together. Purpose of this research is to know thet motivation of host on couchsurfing.com Denpasar area to be a tour guide for the traveler. This reseacrh used qualitative method. Data collected by observation, in-dept interview and literature study. Sampling technique used purposive sampling. The data analyzed through the stages of editing, classification, coding then interpretation. These results indicate that there is a lot of motivations of host couchsurfing.com Denpasar to be a tour guide for the traveler. The main motivations isself-actualization, includes practicing foreign language skills, train travel guides skill, improve personal communication skills, understand the character of the travelers, and dream. The second motivation is esteem needs, prestige and showing hospitality are the part of it. The three last motivation are belongingness and love needs, safety needs, physiological needs.

Keywords: Motivation, Couchsurfing.com, Tour Guide, Traveler

\section{PENDAHULUAN}

Couchsurfing.com atau CS dirilis tahun 2003. Media sosial ini sukses mempertemukan wisatawan dan masyarakat lokal daerah yang dikunjungi di seluruh dunia. Berawal dari mengirim pesan singkat ke account masyarakat lokal (host), wisatawan (traveler) menjelaskan rencana perjalanan selama di destinasi wisata. Host dan traveler akan bertemu secara langsung dan bahkan berwisata bersama. Bagian yang menarik adalah host tidak membebankan harga atas jasanya memandu traveler selama berwisata. Namun, hubungan antara mereka berjalan selayaknya guide dan wisatawan. Saling bertukar pengalaman dan informasi mengenai daerah tujuan wisata. Oleh karena itu, fenomena ini sangat menarik untuk diteliti.

Selain fenomena tersebut, penelitian ini penting dilakukan karena di Indonesia perkembangan couchsurfing makin meningkat terutama di Bali. Pulau dewata sebagai destinasi wisata terkenal di dunia banyak dikunjungi wisatawan asing. Jika couchsurfing dimanfaatkan dengan baik dapat membantu percepatan pertumbuhan pariwisata Bali. Host dapat merekomendasikan akomodasi wisata dan destinasi wisata untuk para traveler. Oleh karena itu penting untuk mengetahui motivasi host

couchsurfing.com area Denpasar menjadi pemandu wisata traveler. Informasi mengenai motivasi host tersebut sebagai bahan pertimbangan masyarakat Bali untuk mengetahui gambaran apa yang akan didapat dari bergabung dengan couchsurfing.com. Masyarakat umum khususnya Bali perlu mengetahui tentang keberadaan couchsurfing.com. Situs ini merupakan salah satu bukti konkret pemanfaatan teknologi dalam bidang pariwisata yang melibatkan langsung masyarakat lokal. Sekaligus dapat membantu kelancaran kegiatan kepariwisataan di Bali karena host dapat merekomendasikan tempat menginap, restoran dan daya tarik wisata kepada traveler. Tujuan penelitian ini adalah untuk mengetahui motivasi host couchsurfing.com area Denpasar menjadi pemandu wisata traveler.

\section{TINJAUAN PUSTAKA}

\section{Konsep Pemandu Wisata}

Secara harfiah pemandu wisata atau yang dalam bahasa inggris "guide". Menurut AP Cowise \& Alan Evison (1980) dalam Sampelan (2015),

"guide is person who shows the other way, something that influences (behavior) with information about places and tools"

Artinya orang yang menunjukkan kepada orang lain tentang jalan, suatu informasi penting mengenai suatu tempat atau cara penggunaan alat.

\section{Konsep Traveler}

Beberapa komponen pokok secara umum disepakati di dalam batasan pariwisata (khususnya pariwisata internasional), yaitu sebagai berikut: 
1. Traveler adalah orang yang melakukan perjalanan antar dua atau lebih lokalitas.

2. Visitor adalah orang yang melakukan perjalanan ke daerah yang bukan merupakan tempat tinggalnya, kurang dari 12 bulan, dan tujuan perjalanannya bukanlah untuk terlibat dalam kegiatan untuk mencari nafkah, pendapatan, atau penghidupan di tempat tujuan.

3. Tourist adalah bagian dari visitor yang menghabiskan waktu paling tidak satu malam di daerah yang di kunjungi, WTO (1995) dalam Pitana (2005)

\section{Teori Motivasi}

Salah satu teori motivasi yang terkenal adalah teori Hirarki Kebutuhan yang dikemukakan oleh Maslow (1943) dalam Purba (2015) mengemukakan bahwa pada dasarnya semua manusia memiliki kebutuhan pokok. Ia menunjukkannya dalam 5 tingkatan yang berbentuk piramid.

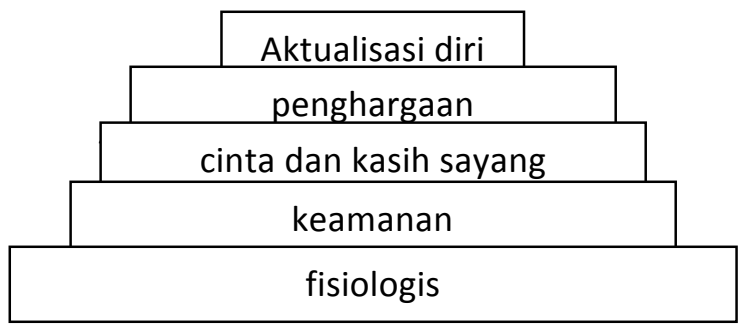

Sumber : Purba (2015)

Kebutuhan fisiologis seperti rasa lapar, rasa haus, dan sebagainya, kebutuhan akan rasa aman yakni merasa aman dan terlindung, jauh dari bahaya. Kebutuhan akan rasa cinta dan rasa memiliki, manusia membutuhkan rasa mencintai dan dicintai orang lain. Kebutuhan akan penghargaan meliputi prestasi, kompetensi diri,dukungan serta pengakuan dari orang lain. Kebutuhan aktualisasi diri yaitu kebutuhan naluriah manusia untuk memanfaatkan kemampuan mereka yang unik dan berusaha menjadi yang terbaik.

\section{METODE PENELITIAN}

Penelitian ini dilakukan di kota Denpasar sebagai daerah yang tingkat keaktifannya paling tinggi di Bali karena jumlah host (CSfer) di Denpasar sebanyak 2341 hosts (Couchsurfing.com, 2017).

Ruang lingkup penelitian mengenai motivasi host couchsurfing.com area Denpasar menjadi pemandu wisata traveler, antara lain :
1. Pemenuhan kebutuhan fisiologis, kebutuhan dasar seperti makan dan minum.

2. Pemenuhan kebutuhan keamanan, rasa aman saat berinteraksi dengan traveler.

3. Pemenuhan kebutuhan cinta dan kasih sayang, ingin merasa dicintai oleh traveler sebagai teman walaupun sebelumnya belum mengenal satu sama lain.

4. Pemenuhan kebutuhan akan penghargaan, host ingin dihargai oleh orang lain karena telah menjadi pemandu wisata traveler.

5. Pemenuhan kebutuhan aktualisasi diri, host ingin mendapat kesempatan untuk mengembangkan potensi diri masingmasing ketika menjadi pemandu wisata traveler.

Metode penelitian yang digunakan dalam penelitian ini adalah metode kualitatif. Teknik pengumpulan mengunakan observasi, wawancara mendalam dan studi kepustakaan, Sugiyono (2007) dalam Prastowo (2014).

Peneliti sendiri. Kriteria-kriteria informan dalam penelitian ini ialah host memiliki wawasan yang luas mengenai CS, pernah menjadi pemandu wisata traveler setidaknya 2 kali dan sering berkomunikasi dengan traveler.

Data yang telah terkumpul dianalisis melalui dua tahap yakni langkah permulaan dan langkah penafsiran. Langkah permulaan dibagi menjadi tiga tahap, yakni editing, pemeriksaan terhadap jawaban-jawaban informan, hasil observasi, dokumen-dokumen memilih foto, dan catatan-catatan lainnya. Kualisifikasi, menggolong jawaban dan data lainnya menurut kelompok variabelnya. Selanjutnya diklasifikasikan lagi menurut indikator tertentu seperti yang ditetapkan sebelumnya. Pemberian kode, pencatatan judul singkat berdasarkan indikator dan variabelnya, serta memberikan catatan tambahan yang dinilai perlu dan dibutuhkan. Langkah selanjutnya adalah penafsiran, data yang sudah diberi kode kemudian ditafsirkan. Analisis data dilakukan dengan memperkaya informasi melalui analisis komparasi (perbandingan) sepanjang tidak menghilangkan konteks aslinya. Hasilnya adalah pemaparan gambar tentang situasi dan gejala dalam bentuk pemaparan naratif (Pohan, 2007 dalam Prastowo, 2014)

\section{HASIL DAN PEMBAHASAN}

\section{Gambaran Umum Couchsurfing.com}


Couchsurfing (CS) adalah situs dan layanan jejaring sosial berupa hospitality exchange atau jaringan silaturahmi. Saat ini, jumlah anggota CS adalah 2,6 juta di 246 negara dan wilayah. Secara etimologi, couchsurfing merupakan suatu neologisme yang mengacu pada praktik perpindahan dari rumah teman yang satu ke rumah teman lainnya, tidur pada ruang senggang apapun yang tersedia, baik lantai maupun sofa (couch), dan umumnya tinggal beberapa hari sebelum pindah ke rumah berikutnya. Misi dari CouchSurfing adalah Create Inspiring Experiences: menampilkan sebuah dunia di mana semua orang dapat mengeksplorasi dan menciptakan hubungan penuh arti dengan orang-orang dan tempat-tempat yang mereka temui. Menciptakan hubungan penuh arti melintasi berbagai budaya memungkinkan untuk menjawab keberagaman dengan keingintahuan, apresiasi, serta rasa hormat. Apresiasi terhadap keberagaman menyebarkan benih toleransi dan menciptakan komunitas global".

Anggota yang telah mendaftar secara gratis akan memiliki pilihan untuk menyediakan informasi, foto dirinya, dan akomodasi inap yang mereka tawarkan jika ada. Informasi yang tersedia lebih banyak akan membuat seseorang cukup percaya bahwa anggota tersebut layak menjadi penjamu (host). Keamanan sering kali diukur dengan keterangan yang ada pada referensi. Setiap traveler yang telah bertemu dengan host dapat mengisi kolom referensi milik host, dan begitu sebaliknya. Pada kolom tersebut keduanya dapat menceritakan pengalaman yang mereka dapatkan saat mereka bertemu.

Rumah singgah (homestay) bersifat sukarela di antara host dan traveler. Urusan durasi, kealamian jamuan, dan jangka waktu menginap tamu umumnya dapat dibicarakan sebelumnya. Transaksi keuangan tidak berlangsung kecuali kompensasi dari pengeluaran yang penjamu keluarkan seperti makanan.

Couchsurfer (sebutan bagi pengguna couchsurfing) dari negara manapun pasti memiliki berbagai motivasi yang membuat mereka bersedia melakukan aktivitas couchsurfer diantaranya hosting, guiding, traveling dan meet up. Aktivitas hosting adalah dimana couchsurfer di daerah destinasi wisata menjamu traveler yang akan menginap di tempat tinggal couchsurfer sekitar wilayah tujuan wisata atau yang disebut host.

Guiding merupakan aktivitas berwisata bersama antara traveler dan host. Seorang couchsurfer yang ada di daerah tujuan wisata, tidak harus bersedia menjamu traveler dengan menerimanya tinggal di tempat tinggal couchsufer untuk bisa melakukan kegiatan guiding. Host yang tidak bersedia menerima traveler menginap juga dapat mamandu wisata (guiding) traveler.

Meet up (bertemu) dilakukan oleh traveler dan host yang memang hanya merencanakan pertemuan saja tanpa hosting dan guiding. Sementara itu, kegiatan yang dilakukan traveler adalah traveling. Ketika couchsurfer akan meninggalkan daerah asalnya untuk berkunjung ke suatu daerah tujuan wisata maka couchsurfer tersebut tengah melakukan traveling.

\section{Motivasi Host Couchsurfing Area Denpasar menjadi Pemandu Wisata Traveler}

Dibawah ini akan dijelaskan motivasi host couchsurfing area Denpasar menjadi pemandu

wisata traveler sesuai dengan teori hirarki kebutuhan yang dikemukakan oleh Maslow, 1943 dalam Purba (2015) :

\section{Pemenuhan kebutuhan fisiologis}

Couchsurfer area Denpasar mengaku bahwa selama beraktivitas bersama traveler baik itu berwisata ataupun sekedar meet up , kebutuhan host sebagian besar dipenuhi oleh traveler. Seperti biaya makan, tiket masuk, bensin kendaraan ketika berwisata di luar. Begitu pula biaya kopi dan makan saat bertemu dengan traveler di sebuah restoran atau cafe bagi host yang hanya meet up tanpa berwisata bersama. Namun, hal itu dinilai hanyalah bonus yang dapatkan oleh host karena telah berbagi informasi kepada traveler. Pemberian fasilitas oleh traveler kepada host bukan menjadi motif ekonomi utama bagi host bersedia menjadi pemandu wisata traveler. Couchsurfer dalam couchsurfing tidak pernah mengorientasikan pelayanan yang diberikan kepada couchsurfer lain dengan uang.Hal ini didukung dengan pernyataan salah satu host ;

"Bila saya menemani traveler keliling pantai-pantai di Bali. Traveler tidak perlu membayar jasa saya karena telah bersedia menjadi pemandu wisata. 
Hanya saja, dia mengerti tentang kebutuhan makan, minum saya, bensin motor jika menggunakan motor saya. Segala sesuatu mengenai kebutuhan penting saya pasti traveler akan berusaha untuk memenuhinya. Kalau tidak menguntungkan secara komersil, yang penting jangan merugikan". (Trisna, 21 tahun).

\section{Pemenuhan kebutuhan kemanan}

Sebelum host dan traveler bertemu, keduanya belum saling mengenal, namun sudah merasa aman jika bertemu atau berwisata bersama. Hal ini karena host ataupun traveler dapat mengetahui profil dan referensi dari couchsurfer yang pernah ditemui. Sehingga perasaan aman dirasakan oleh host saat bertemu traveler yang baru dikenal. Hal ini dibuktikan dengan pernyataan host dibawah ini ;

"Kita sebagai host, harus hati-hati dalam menerima traveler. Di couchsurfing kami memiliki standar keamanan sendiri, yakni referensi masing-masing couchsurfer, jika couchsurfer memiliki referensi yang positif dan banyak. Maka dapat dikatakan kalau couchsurfer tersebut aman untuk di temui atau diajak berwisata bersama" (Memey, 21 tahun)

\section{Pemenuhan kebutuhan cinta dan kasih sayang}

Bertemu dengan orang baru (traveler) dari berbagai negara di seluruh dunia adalah alasan mendasar para host bersedia menerima permintaan traveler untuk menjadi pemandu wisata mereka. Host dan traveler berkomunikasi langsung dan mengenal satu sama lain selama aktivitas pertemuan atau wisata. Bercerita mengenai daerah asal daerah asal masingmasing, hobi dan informasi seputar daerah destinasi wisata traveler dalam hal ini adalah Bali. Hubungan pertemanan yang terjalin dari awal perkenalan hingga pertemuan biasanya masih tetap berlangsung bahkan setelah traveler kembali ke daerah asalnya. Host merasa dicintai oleh traveler sebagai teman, karena traveler masih menjaga hubungan persahabatan bahkan setelah traveler pergi dari daerah tujuan wisata. Hal ini dibuktikan dengan kutipan wawancara dengan salah satu hostcouchsurfing area Denpasar bernama Memey 21 tahun.
"Saya merasa senang sekali bisa guiding traveler. Baik itu perempuan atau lakilaki. Mereka baik, sopan, lembut dan menganggap saya seperti keluarganya sendiri. Mereka juga bilang kalau saya adalah keluarga mereka di Indonesia. Layaknya sebuah keluarga atau sahabat, kami bercerita tentang apapun yang kami ingin ceritakan termasuk kisah cinta kami."

\section{Pemenuhan kebutuhan penghargaan}

Motivasi host untuk memenuhi kebutuhan akan penghargaan terbagi menjadi 2 macam, yaitu penghargaan secara prestige dan penghargaan atas hospitality yang ditunjukan untuk traveler. Secara rinci akan dijelaskan di bawah ini ;

\section{a. Prestige}

Memiliki teman baru yang berasal dari berbagai daerah dan negara sebelumnya tidak pernah terpikirkan oleh host. Sebelumnya, pertemanan mereka hanya sebatas teman sekolah, teman kuliah, teman bermain yang tinggal tidak jauh dari tempat tinggal host dan keluarga host. Sebagian besar host sebelum bergabung dengan couchsurfing sudah banyak yang memiliki teman yang tersebar di Indonesia namun tetap saja teman-teman tersebut juga berasal dari daerah asal yang sama dengan host. Karena alasan mencari pekerjaan atau kuliah sehingga teman tersebut menyebar ke berbagai daerah di Indonesia. Sehingga sebelum bergabung couchsurfing, host belum pernah memiliki teman yang memang baru dikenal, apalagi teman internasional. Setelah mengetahui bahwa couchsurfing adalah situs jejaring sosial bagi traveler dari seluruh dunia maka host bergabung dengan couchsurfing.

Memiliki teman baru dari berbagai daerah di Indonesia dan teman internasional dari berbagi negara membuat host merasa bangga. Host merasakan adanya prestige ketika mereka mampu berteman dengan traveler terutama traveler dari negara lain. Karena tidak semua orang dapat memiliki teman dari negara lain. host ingin mendapat pengakuan dari orang lain bahwa host mampu berteman dengan orang dari luar negeri. Trisna (21 tahun) salah satu host memaparkan bahwa 
prestige menjadi salah satu motivasinya untuk menjadi pemandu wisata traveler,

"Hanya sedikit dari teman-teman saya yang punya teman internasional. Karena mereka tidak pernah bertemu dan tidak tau tentang couchsurfing ini. Teman kampus sih sudah ada beberapa yang punya teman orang luar negeri tapi jumlahnya tidak banyak. Jadi, saya merasa lebih beruntung karena pergaulan saya lebih luas sampai ke Eropa, Asia, Amerika. Teman saya juga ada yang bilang kalau enak jadi saya kalau saya hidupnya senang karena punya teman banyak dari luar negeri”.

\section{b. Menunjukkan hospitality}

Host juga menyatakan bahwa menjadi couchsurfer yang teliti dan murah hati adalah sebuah keharusan untuk memberikan kesan positif kepada traveler. Traveler yang puas terhadap pelayanan host akan memberikan referensi positif kepada host. Menunjukkan hospitality kepada traveler untuk mengenalkan budaya kebiasaan host adalah motif sosial lain yang diinginkan oleh host. Couchsurfer yang akan hosting akan berusaha sebaik mungkin dalam melayani traveler. Selain untuk menunjukkan hospitality orang Indonesia, juga agar traveler meninggalkan referensi positif kepada host. Referensi menjadi salah satu indikator yang paling diperhatikan oleh host dalam menerima atau menolak couchrequest dari traveler. Oleh karena itu couchsurfer berusaha untuk menjadi couchsurfer yang teliti dan murah hati agar tidak mendapat penilian buruk dari couchsurfer lain. Agar jika kelak mengirim couchrequest ke couchsurfer lain mudah diterima. Selain dari referensi, umumnya couchsurfer yang hendak menemui couchsurfer lain meninjau profil couchsurfer yang akan ditemui. Pernyataan dari Cencia (22 tahun) host CS area Denpasar mengenai motivasi menunjukkan hospitality kepada traveler, sebagai berikut ;

"Saya senang bisa hosting, karena saya bisa berbagi tentang cara hidup Indonesia, kebiasaan orang Indonesia dengan segala keramahtamahannya. Agar traveler tau bahwa orang Indonesia itu ramah-ramah."

\section{Pemenuhan kebutuhan aktualisasi diri}

Aktualisasi diri adalah upaya untuk mengembangkan potensi diri untuk menjadi individu yang lebih baik. Host memiliki keinginan untuk mengembangkan potensi diri ketika menjadi pemandu wisata traveler. Berbagai potensi diri berusaha dikembangkan host, antara lain ;

\section{a. Mengasah kemampuan berbahasa asing}

Host bersedia menjadi pemandu wisata bagi traveler selain untuk menambah teman baru juga untuk mengasah kemampuan bahasa asing mereka terutama bahasa inggris. Karena bahasa inggris menjadi bahasa universal yang digunakan couchsurfer dalam berkomunikasi. Selain bahasa inggris, host juga melatih berbahasa asing lain seperti Jepang, China, Arab dan Prancis ketika bertemu dengan traveler yang mahir berbahasa tersebut. Hal ini dibuktikan dangan pernyataan salah satu narasumber ;

"Selain guiding traveler, saya juga
belajar bahasa kepada mereka.
Terutama bahasa Inggris, jepang, China,
Prancis. Semua bahasa itu sedang dalam
proses pembelajaran. Oleh karena itu
saya sangat suka jika ada traveler yang
mahir dua bahasa tersebut minta saya
guiding atau hosting, hitung-hitung
belajar bahasa asing gratis". Cencia ( 22
tahun)

b. Melatih kemampuan memandu wisata

Selain bahasa, host juga mengasah kemampuan memandu wisata bagi yang nanti akan terjun ke sektor pariwisata ketika bekerja. Motivasi aktualiasasi diri dengan cara mengasah keahlian memandu wisata juga telah dipenuhi oleh hostdalam memandu wisata traveler. Trisna (21 tahun), salah satu narasumber yang juga berprofesi sebagai mahasiswa fakultas pariwisata UNUD menggungkapkan secara jelas tentang melatih kemampuan memandu wisata sebagai motivasi untuk guiding traveler di bawah ini ;

"Saya di kampus belajar pariwisata, kenapa tidak saya praktekkan pada waktu saya 
mandu wisata mereka. Kan lumayan selain jalan-jalan juga bisa praktek lapangan"

c. Meningkatkan kemampuan komunikasi interpersonal

Wiryanto (2004) dalam jurnal Dewanti (2014) mengartikan bahwa komunikasi interpersonal merupakan komunikasi dari mulut ke mulut yang terjadi ketika saling bertatap muka antar individu. Komunikasi interpersonal sebenarnya merupakan proses sosial dimana saling mempengaruhi individuindividu yang terlibat di dalamnya. Oleh karena itu saat berkomunikasi interpersonal, host dan traveler saling mempengaruhi tentang apapun.

Misalnya traveler meminta rekomendasi restoran makanan khas Bali yang enak kepada host. Kemudian host mendata beberapa restoran yang menyediakan makanan Bali berkualitas dan memilih satu restoran untuk disingahi. Dengan begitu, host mempengaruhi traveler untuk memilih restoran tersebut untuk makan. Belajar meningkatkan kemampuan berkomunikasi lancar dengan orang asing tanpa gugup juga dilakukan. Semakin sering berkomunikasi, maka host semakin terbiasa berbicara dengan orang asing agar traveler yakin atas kebenaran informasi yang diberikan host. Memey (21 tahun) host couchsurfing area Denpasar menceritakan tentang keinginannya untuk melatih kemampuan interpersonalnya di bawah ini ;

"Sering berkomunikasi dengan orang itu penting. Agar nanti jika sudah masuk di dunia kerja. Bisa lancar berkomunikasi dengan orang lain misalnya klien kerja atau rekan kerja maupun atasan dengan maksud ingin meyakinkan lawan bicara terhadap apa yang kita katakan. Apalagi saya rencananya mau kerja di luar negeri yang notabene menggunakan bahasa inggris sebagai bahasa yang universal. Oleh karena itu, saya mencoba melatih kemampuan meyakinkan orang lain atas ucapan saya pada saat memandu wisata para traveler."

\section{d. Memahami karakter traveler}

Keinginan untuk memahami karaktertraveler yang berasal dari berbagai daerah. Tujuannya adalah agar tau cara menyikapi traveler selama bertemu atau berwisata. Kemampuan memahami karakter orang lain harus dilatih terus menerus agar tahu bagaimana harus bersikap dengan masing-masing orang dari negera yang berbeda-beda. Pernyataan ini bersumber dari salah satu host CS area Denpasar yaitu Cencia (22 tahun) ;

"Alasan saya join di website keren ini dan bersedia menjadi pemandu wisata dengan cara meet up bersama traveler, adalah karena saya ingin tau bagaimana sifat mereka. Mengingat traveler yang saya temui itu bukan orang Indonesia. Saya berfikir pasti mereka mempunyai sifat, kebiasaan, dan kesukaan yang berbeda dari orang Indonesia. Oleh karena itu pasti menyenangkan jika saya bisa bertemu mereka dan bisa paham bagaimana kepribadian bule itu".

\section{e. Mimpi atau cita-cita}

Host memiliki mimpi yang dicita-citakan. Mimpihost yakni keliling dunia, mengunjungi tempat traveler yang pernah ditemui di Bali. Memiliki bisnis yang melibatkan masyarakat dunia yang akan dibangun nanti dan mulai untuk mengenalkan bisnis tersebut kepada traveler.

Beberapa host mengungkapkan bahwa mereka ingin merealisasikan mimpi-mimpi mereka yang belum bisa terwujud saat sekarang. Host berpikir dengan memperluas jaringan melalui couchsurfing makan peluang untuk mewujudkan mimpi-mimpi tersebut semakin terbuka.Seperti pengakuan dari host di bawah ini ;

"Aku punya mimpi keliling dunia, seperti mereka (traveler) . Bisa jalan-jalan ke seluruh wilayah di dunia. Karena saya sudah sering hosting dan guiding traveler, saya berharap saya juga bisa tinggal di rumah couchsurfer kalau saya mau pergi ke suatu destinasi wisata." (Cencia, 22 tahun).

\section{SIMPULAN DAN SARAN}

\section{Simpulan}

Couchsurfing (CS) adalah situs jejaring sosial yang beranggotakan traveler dari seluruh dunia. Mempertemukan masyarakat lokal (host) dengan wisatawan (traveler) di sebuah daerah tujuan wiasta. Couchsurfing memiliki misi Create Inspiring Experiences yang artinya 
menciptakan pengalaman yang inspiratif. Motivasi host couchsurfing area Denpasar menjadi pemandu wisata traveler paling dominan adalah pemenuhan kebutuhan aktualisasi diri. Berbagai macam usaha pengembangan potensi diri dilakukan oleh host, yakni mengasah kemampuan berbahasa asing, melatih kemampuan memandu wisata, meningkatkan kemampuan komunikasi interpersonal, memahami karakter traveler, mimpi atau cita-cita. Aktualisasi diri menjadi motivasi utama karena host menginginkan dapat melaksanakan kelima tujuan di atas yang dapat mengembangkan potensi diri mereka saat menjadi pemandu wisata traveler. Motivasi terbesar selanjutnya adalah pemenuhan kebutuhan penghargaan, terbagi menjadi dua, penghargaan atas prestige dan penghargaan atas hospitality yang ditunjukkan kepada traveler. Motivasi ini menjadi motivasi terbesar kedua karena terdapat dua macam tujuan yang ingin dicapai oleh host dalam pemenuhan kebutuhan penghargaan. Pemenuhan kebutuhan rasa cinta dan kasih sayang, keamananan dan fisiologis menjadi tiga motivasi yang berada di bawah. Ketiga motivasi tersebut menjadi tiga motivasi terbawah karena host hanya memiliki satu tujuan pada masingmasing kebutuhan tersebut. Penempatan urutan ketiga motivasi tersebut juga berdasarkan urutan motivasi dari yang tertinggi ke terendah sesuai teori Maslow (1943) dalam Purba (2015).

\section{Saran}

Berdasarkan penjelasan di atas, maka dapat diberikan beberapa saransebagai berikut:

1. Host dapat menghadirigathering yang sering dilakukan oleh komunitas couchsurfing di daerah tinggal host agar mengenal couchsurfer yang juga berdomisili di daerah yang sama. Sehingga lebih memperluas jaringan lebih sering berinteraksi dengan couchsurfer.

2. Host diharapkan untuk membentengi diri sehingga tidak perpengaruh budaya traveleryang dapat melanggar norma dan nilai budaya Indonesia .

3. Mendukung kegiatan pariwisata berkelanjutan dengan merekomendasikan destinasi wisata ataupun akomodasi wisata yang sustainable.

4. Masyarakat Bali yang menyukai traveling dapat bergabung dengan couchsurfing agar semakin banyak host yang dapat mempromosikan Bali secara langsung kepada traveler.

5. Lakukan penelitian lanjutan mengenai persepsi traveler terhadap kualitas host couchsurfing area Denpasar. Sebagai penilaian atas perlakuan host area Denpasar.

\section{DAFTAR PUSTAKA}

Dewanti, Amelia Ratih.2014.'Hubungan antara kepercayaan Diri dalam Berkomunikasi dengan Komunikasi Interpersonal".ALIBKIN (Jurnal Bimbingan Konseling). Vol.3No.1.

Khalik, Wahyu. 2014. Kajian Kenyamanan dan Keamanan Wisatawan di Kawasan Pariwisata Kuta Lombok. JUMPA. Vol 01 No 01

Sampelan, Shinta N. 2015. "Pramuwisata di Kota Manado". Jurnal Holistik. Tahun VIII No 15.

Pitana, I Gede dan Putu G Gayatri. 2005. "Sosiologi Pariwisata". Yogyakarta : Andi.

Prastowo, Andi. 2014. "Metode Penelitian Kualitatif dalam Perspektif Rancangan Penelitian". Yogyakarta : Ar-Ruzz Media.

Purba, Christy Ulina. 2015. "Motivasi Kunjungan Wisatawan Taman Hutan Raya Sultan Syarif Hasyim Pekanbaru Riau". Jurnal Online Mahasiswa Fakultas Ilmu Sosial dan Ilmu Politik. Vol 2 No 1.

Couchsurfing.com diakses 20 Januari2017 